\title{
Emotional Distress in the Early Stages of the Corona Related Lockdowns Depending on the Severity of the Pandemic and Emergency Measures: $A$ Comparative Online-survey in Germany, Austria and Italy
}

Christiane Eichenberg ( $\nabla$ c.eichenberg@sfu.ac.at)

Sigmund Freud University Vienna

Martin Grossfurthner

Sigmund Freud University Vienna

Sybille Kietaibl

Sigmund Freud University Vienna

\section{Greta Riboli}

Sigmund Freud University, Milano

\section{Rosita Borlimi}

Sigmund Freud University, Milano

\section{Stefana Holocher-Benetka}

Sigmund Freud University Vienna

\section{Research Article}

Keywords: COVID-19, Lockdown, Emergency Measure, Online Survey

Posted Date: February 4th, 2021

DOI: https://doi.org/10.21203/rs.3.rs-155804/v1

License: (c) (i) This work is licensed under a Creative Commons Attribution 4.0 International License.

Read Full License 
Emotional distress in the early stages of the corona related lockdowns depending on the severity of the pandemic and emergency measures: A comparative online-survey in Germany, Austria and Italy

Christiane Eichenberg $^{1 *}$, Martin Grossfurthner ${ }^{2}$, Sybille Kietaibl $^{3}$, Greta Riboli $^{2,4}$, Rosita Borlimi ${ }^{4}$ \& Stefana Holocher-Benetka ${ }^{2}$

${ }^{1}$ Institute of Psychosomatics, Faculty of Medicine, Sigmund Freud University, Vienna, Austria

${ }^{2}$ Faculty of Psychology, Sigmund Freud University, Vienna, Austria

${ }^{3}$ Faculty of Medicine, Sigmund Freud University, Vienna, Austria: Evangelical Hospital Vienna, Austria

${ }^{4}$ Faculty of Psychology, Sigmund Freud University, Milano, Italy

\section{* Correspondence:}

Christiane Eichenberg

c.eichenberg@sfu.ac.at 


\begin{abstract}
Background: The first wave of the COVID-19-pandemic hit different countries with varying degrees of severity, so that differences in the type and level of emergency measures were also necessary. It can be assumed that the psychological burden was higher in countries with a more severe process of the pandemic (Italy) than in countries with a less severe (Germany,
\end{abstract} Austria).

Objective: To investigate und contrast the wellbeing of the population in Italy, Austria and Germany in the early phase of the first lockdown.

Method: Online survey on $\mathrm{N}=4289$ individuals. The questionnaire comprised

1. self-administered section, exploring the dimensions perceived severity of COVID-19, perceived risk of disease, concerns related to COVID-19, emergency measures acceptance and emotional distress due to emergency measures

2. standardized scales to record personality determinants: Stress-CopingStyle-

Questionnaire, Positive and Negative Affect Schedule, State-Trait-Anxiety-Inventory. Results: The three countries displayed significant differences in all personality dimensions. Italian participants assessed the COVID-19 virus as much more dangerous, but despite the prevalence of the virus, the subjective risk of disease is perceived to be lower in Italy. This could be a positive effect of the restrictive curfews set by the government in Italy. The emergency measures were generally perceived to be very effective in all three countries, but due to duration and the severity of the measures the fear and stress-reaction was the strongest within the Italians.

Conclusion: The stricter measures in Italy prevented an application of many positive stress processing strategies, which, in turn, fostered the preservation of stresses and fear.

Keywords: COVID-19, Lockdown, Emergency Measure, Online Survey 


\section{Introduction}

Since the outbreak of the COVID-19 crisis, severe medical challenges, as well as it's mental and social consequences, determine public life. The whole world is confronted with a pandemic of global scope. Worries and fears during this crisis are shaped individually and concern various aspects of life, including health, employment and social relations (4). The first lockdown - which started on the 08.03.2020 in Italy, 16.03.2020 in Austria and 23.03.2020, in Germany and lasted 7 weeks in Austria and Germany and 10 weeks in Italy constituted a unique situation. It was followed by a phase of an incremental loosening of the emergency measures. However, "normality" cannot be expected in the near future. The infection rates have been rising again in many countries, including Italy, Austria and Germany, since August 2020 leading to a new lockdown in these countries starting at beginning of November 2020. So far, the course of the COVID-19 pandemic has been cyclical, characterized through highly acute phases and phases of moderate infection rates. Each phase was accompanied by respective statutory emergency measures. In order to assess the psychosocial impacts of the pandemic on the overall population in general as well as on vulnerable groups in particular, it is necessary to conduct studies that capture these stresses in the different phases of the pandemic. The lockdown thereby constitutes a particular phase with the most sever social restrictions.

\section{Current state of research on the psychological impacts of the lockdown}

The research activity on COVID-19 related questions was enormous within all disciplines able to contribute. This is illustrated by a data inquiry of "PubMed" for the medical field. On 04.11.2020, the search term "COVID" lead to more than 66.000 hits. If narrowed down to "COVID \& lockdown", more than 2.500 hits were attained at the same point in time. The very specific search for "COVID \& lockdown \& psychological impact" still lead to 181 results. It 
is thus no surprise that there already exist metanalyses summarizing the results of studies on the psychological stresses within the respective countries (e.g. for China see 30).

These 181 publications do not only comprise country-specific studies, like on Italy $(23,7,24)$, Spain (27), Nepal (13), China (29) and Africa (18), but also cross-sectional studies accounting for mental impacts on the overall population (e.g. 28, 9) as well as on specific sociodemographic groups such as students (25), vulnerable groups like the elderly (21), migration workers (19) and doctors (e.g. 34 for Italy), or clinical groups, like psychiatric patients (14), children and adolescents with ADHD (5), patients with migraine (26) or sleep apnea (1) Longitudinal studies looked at the prevalence of mental disorders before and during the lockdown (see 28 for the United Kingdom), while retrospective studies analyzed in how far and what kinds of suicides that took place during the lockdown can be traced back to this peculiar situation (8).

The studies can be further differentiated with regards to their outcome measures and the moderating variables included. They measure, for example, clinical stresses such as fear, depression, or psycho-traumatic symptoms as well as health-psychological variables like the impacts on sleep (22), sexual activity (16) or online play behavior as a coping mechanism (2). Moderating variables were included to identify certain risk and protective factors, operationalized, e.g., through attachment style and affective temperament (23). Genetic influencing factors were compared to environmental influences using twin studies (31).

Besides questionnaires, psycholinguistic methods were used, like in the study by Su et al. (35), which analyzed the changes in psycholinguistic trades of social media posts before and after the lockdown in Wuhan (analyses of posts on Weibo) and Lombardy (analysis of posts on Twitter). Thus, cross-country comparisons were conducted to detect potential culturally specific ways of dealing with a lockdown. However, according to our knowledge, there exists no study assessing the emotional wellbeing in as well as the resilience to the pandemic crisis within the population of different countries experiencing the pandemic to varying degrees of 
severity and consequently facing different lockdown phases. In a European comparison, Italy was hit the hardest in the first phase of the pandemic, counting 3405 COVID-19 related deaths

on the

(https://opendathunadpc.maps.arcgis.com/apps/opsdashboard/index.html\#/b0c68bce2cce478e aac82fe38d4138b1), and thus for the first time more victims than China. At the same point in time, there were only two deaths in Austria (https://en.wikipedia.org/wiki/COVID19 pandemic in Austria) and not a single one in Germany (https://en.wikipedia.org/wiki/Template:COVID-

19 _pandemic_data/Germany_medical_cases_chart).

Due to the degree of severity with which Italy was affected, the lockdown was not only in place for longer, its measures were also more restrictive than the once implemented in Germany and Austria. While the people in these countries continued to be allowed to leave their apartments for work-related reasons and people in Germany could, for example, do sports with another member of the same household (see the German SARS-CoV-2 regulation on containment measures from March, 172020 of the federal state of Berlin: https://www.berlin.de/sen/justiz/service/gesetze-und-verordnungen/2020/ausgabe-nr-12-vom27-3-2020-s-217-224.pdf\#page=4) and the house could likewise be left covering basic needs, which includes mental and physical recreation in Austria (https://www.lbg.at/servicecenter/lbg_steuertipps_praxis/corona_virus bundesweit einheitlic he_verkehrsbeschränkungen_ab_16_märz_bis_22_märz_2020/index_ger.html), the measures set in Italy were much more far-reaching. At the time of our study, the population was only permitted to leave the house for the following reasons: work-related reasons if working within a system-relevant job, individual walks no further than 200 meters away from the place of residency, going to the hospital or visiting a doctor in cases of emergency, shopping in open supermarkets and essential shops (e.g., pharmacies, tobacco shops) (http:/www.governo.it/it/articolo/coronavirus-firmato-il-dpcm-22-marzo-2020/14363). 
We conducted an online survey in the early phase of the first lockdown in Italy, Germany and Austria in order to contrast the emotional wellbeing of the population of these countries. We aimed at capturing the perceived danger of the virus, the specific concerns and stresses as well as the resilience of the populations in the respective country. Likewise, the usage of apps for compensatory stress management, as well as a potential change in attitudes toward social media as a means of communication with family and friends, were surveyed.

We hypothesize that within the Italian population - the population of a country, which experienced the pandemic very severely and consequently implemented very restrictive emergency measures - the virus is not only assessed to be more dangerous but also the stresses in terms of worries, fear, and negative emotions are higher than among the Austrian and German population. Due to the considerably more restrictive measures, we additionally assume, that in Italy digital media is used to a larger extent for compensatory stress management (e.g., mental health apps) and that - as in this country no social-physical contacts were possible - social media was used as a social compensation. This could cause a change of attitudes towards these media.

We thus contrasted the Italian with the German and Austrian population in respect to the following questions:

- How dangerous is the virus perceived to be?

- How high is the subjective risk of disease perceived in dependency on the emergency measures?

- How does the acceptance of the statutory emergency measures develop and which emotions accompany the respective measures?

- Which effects do the statutory measures have on fear and emotional wellbeing of the population?

- Which coping strategies can become effective under the respective measures? 


\section{Materials and Method}

\section{Study Design}

The Austrian, German and Italian populations were invited to participate in an online survey via social media and newspapers. We used the online survey SoSci (https://www.soscisurvey.de) for data collecting. A pre-test with ten participants allowed us to interpret the results in order to improve feasibility, intelligibility, and comprehensiveness. The survey was available online from March 22 to 29 (beginning of the lockdown in Italy: March 8, 2020; beginning of the lockdown in Austria: March 16, 2020; beginning of the lockdown in Germany: March 23, 2020). Participants received information about study design and data protection before filling in the questionnaire. The duration of the questionnaire was about 25 minutes. The Ethics Commission at Sigmund Freud University Vienna approved this study (date of approval: March 18, 2020).

\section{Instruments}

Participants filled in a self-administered questionnaire, which included sociodemographic data and various sets of questions concerning the COVID19-pandemic (see Appendix)

\section{Socio-demographic data}

Besides information on gender (male/female/diverse), age (in years; retrospectively subsumed in 6 groups: 18-29/30-39/40-49/50-59/60-69/ 70 + year-old) and highest educational level (7 categories from "no graduation" to "university degree") we asked for annual income (up to $25.000 € / 25.000-40.000 € / 40.000-70.000 € / 70.000-100.000 € />100.000 €)$ and the number of people per household.

\section{Covid19-pandemic questionnaire}


Perceived severity of COVID19 (2 items): "The coronavirus is harmless - dangerous" (5-point Likert scale) "The coronavirus is comparable to influenza - more dangerous than influenza" (5-level Likert scale);

Perceived risk of disease (3 items on the danger of the virus itself, the risk of becoming ill, and the risk of transmitting the infection), e.g., "To which extent are you susceptible of catching COVID19?" (5-point Likert scale); The internal consistency (Cronbach's alpha) in our sample is $\alpha=.60$.

Emotional distress due to emergency measures (10 items on negative feelings related to the behavioral measures), e.g., "Self-isolation due to the coronavirus makes me angry" (5-point Likert scale); The internal consistency (Cronbach's alpha) in our sample is $\alpha=.87$.

Emergency measures acceptance (15 items on the assessment of the value and efficacy of behavioral measures: self-isolation, quarantine, traveling restrictions, smart working, cancellation of events), e.g., "Self-isolation due to coronavirus is reasonable" (5-level Likert scale), "Self-isolation from the coronavirus can prevent it from spreading" (5-point Likert scale); The internal consistency (Cronbach's alpha) in our sample is $\alpha=.90$.

Concerns related to the COVID19-pandemic (8 items on concerns about health, society, and economy), e.g., "I am concerned about the health of my relatives/ friends" (5-point Likert scale); The internal consistency (Cronbach's alpha) in our sample is $\alpha=.64$.

E-mental health usage (4 items on app-usage for stress management, overcoming fears, socializing and other), e.g., "I am using apps for overcoming my fears" or "I am using apps to keep in contact with others" (dichotomy); one question on the change of attitudes towards social media; 
We used standardized scales in the following order to capture current emotional wellbeing (affects, fear) and possibilities of stress management (coping styles):

Assessment of current emotional wellbeing: We adapted the German version of the Positive and Negative Affect Schedule - PANAS from the one developed in 1988 by Watson, Clark, and Tellegen (36) to measure emotional states. It consists of twenty adjectives that describe different emotions and feelings. The two groups of ten terms are accurate markers of either positive or negative affect, and subjects assess their intensity on a five-point scale from "not at all" to "extremely". The internal consistencies (Cronbach's alpha) for both subscales are $\alpha>$ .84. To design a questionnaire of reasonable length, we only included the items on negative affect.

Assessment of stress management strategies: Stress Coping Style Questionnaire - SVF 78 (10): This questionnaire evaluates coping styles and processing patterns in stressful situations. It is composed of 13 subscales, each describing reactions to stress in terms of time and situation-stable (stressor) personal characteristics. The internal consistencies (Cronbach's alpha) of the SVF subtests result are between $\alpha=.77$ and $\alpha=.94$.

Assessment of current anxiety: State-Trait Anxiety Inventory - STAI (20): This is a standard tool in anxiety and stress research consisting of two subscales incorporating 20 items (4points Likert scale) to differentiate anxiety as a state and as a trait. The internal consistency for both subscales is $\alpha=.90$. Since we were only interested in the current condition, we only used the state-scale.

\section{Participants}

6334 Austrians, Germans and Italians registered via the dedicated link during the survey validity period. $12.55 \%$ of the participants $(N=795)$ did not complete the first page, on which participants were informed on the content of the study as well as on the data processing and 
were asked to give written consent to the participation in the study. Only about $5.89 \%(N=$ 294) of Austrians and Germans and 4.67\% $(N=62)$ of Italians abandoned the questionnaire after the second page, on which socio-demographic data was collected. The overall dropout rate of $32.29 \%(N=2045)$ is acceptable (33). The actual sample size, after excluding all invalid cases or dropouts, consisted of $N=4289$ data sets (Germany: $\mathrm{n}=704$, Austria: $\mathrm{n}=$ 2359 , Italy: $\mathrm{n}=1226$ ) and were therefore included in the evaluation.

\section{Statistical Analysis}

We used the Statistical Package for the Social Sciences Program (SPSS Version 24) for data input, processing, and statistical analyses.

First, we performed goodness-of-fit tests to get an overview of the data. The distribution of all questionnaire-scores deviated in at least one of each group significantly from normality (Kolmogorov-Smirnov and Shapiro-Wilk $>.05)$. As a consequence, we performed KruskalWallis Tests, followed by pairwise Post-hoc-Tests to compare the COVID-19 scales Perceived risk of disease, Perceived severity of COVID19, Emergency measures acceptance and Emotional distress due to emergency measures between age and income groups. It was of interest whether sociodemographic variables have an influence on the assessed questionnaire scales independently of the country affiliation and might thus influence the results of the cross-country comparison.

Finally, Kruskal-Wallis Tests, followed by post-hoc-tests, were performed to compare scores of the COVDI-19-scales and scores of the PANAS-, STAI- and SVF78-scales between the three countries.

\section{Results}




\section{Demographics}

The gender distribution shows a higher proportion of women with 2911 female respondents (68\%), 1332 male participants (31\%), and 46 subjects (1\%) who did not specify their gender. The average age was 35.2 years $(S D=12.04)$. The distribution of the sociodemographic variable "highest educational level" also shows that the sample at hand has an unusually high level of education: $35.8 \%$ had a general qualification for university entrance, $60.2 \%$ a university degree. A total of 783 respondents declared living alone (18.3\%), the rest was cohabiting, for the most part in a two-person household (2345 people or $54.7 \%$ ). Approximately a quarter of the participants live with one or more children.

The three countries (Italy, Austria, Germany) exhibit an even distribution with regards to educational level $\left(\chi^{2}(2)=3.06, \mathrm{p}=.217\right)$ and gender $\left(\chi^{2}(2)=1.06, \mathrm{p}=.209\right)$. There is a significant difference regarding age $\left(\chi^{2}(2)=20.87, \mathrm{p}=.000\right)$. The Austrian sample contains significantly younger participants than the Italian sample. In regards to income, all three countries differ significantly $\left(\chi^{2}(4)=168.21, p=.000\right)$, the annual income being the highest in Germany and the lowest in Italy. This is in accordance with statistics on the average gross monthly earnings, which is significantly lower in Italy than in the other two countries (e.g., https://de.statista.com/statistik/daten/studie/183571/umfrage/bruttomonatsverdienst-in-der$\mathrm{eu} /)$

\section{COVID-19 questionnaire scores in sociodemographic comparison}

The virus is perceived as dangerous in the whole sample. The Perceived severity of COVID19 median value is 8 out of $10(M=8.22, S D=1.47)$. Kruskal-Wallis tests results show significant differences between the different age groups $\left(\chi^{2}(4)=151.47, p=.000\right)$, MannWhitney-U tests prove differences between the age-groups of 50+ year-olds and all younger groups (18-49 years). Older people perceive the virus as significantly more dangerous. The situation is different in the assessment of the Perceived risk of disease $(M=8.58, S D=2.34)$. 
Here too, significant differences between age groups appear $\left(\chi^{2}(4)=36.97, p=.000\right)$. However, the post-hoc-tests show that the two youngest groups (18-29 years and 30-39 years) report a significantly higher risk of disease than all others. Within the different income groups and between genders no significant differences regarding the perceived danger of COVID-19 and the subjective risk of disease can be detected (Danger of Covid-19: income $\left(\chi^{2}(4)=8.95\right.$, $\mathrm{p}=.062)$, gender: $\left(\chi^{2}(2)=1.54, \mathrm{p}=.462\right)$; Subjective risk of disease: income: $\chi^{2}(4)=5.57, \mathrm{p}$ $=.234$; gender: $\left.\chi^{2}(2)=3.91, p=.142\right)$.

Emergency measures implemented by the Austrian, German and Italian governments are considered to be highly effective. The Acceptances median value is 72 out of $75(M=69.76$, $S D=6.42$ ), revealing a high level of endorsement. Kruskal-Wallis tests results show no significant differences between the different age groups $\left(\chi^{2}(4)=2.77, p=.596\right)$. Regarding to the income groups, differences can be found $\left(\chi^{2}(4)=14.93, \mathrm{p}=.005\right)$ and the MannWhitney-U tests prove differences between all the income groups with low to lowest income in comparison to higher income groups. Those people show a lower level of acceptance. Furthermore, gender differences can be found $\left(\chi^{2}(2)=36.47, p<.001\right)$. Post-hoc MannWhitney-U tests show that women ascribe more acceptance to the measures than men $(\mathrm{z}=$ $5.70, \mathrm{p}<.001)$. Besides the broad approval of the governments' action, the level of discomfort stemming from the restrictive measures (Emotional distress due to emergency measures) remains relatively low. A skewed distribution is observed, with a median of 14 out of $50(M=$ $16.34, S D=6.68)$. Nevertheless, this essentially positive picture does not apply to all groups to the same extent. The Kruskal-Wallis test shows different levels of emotional distress between different age $\left(\chi^{2}(4)=31.97, p<.001\right)$, income $\left(\chi^{2}(4)=31.97, p<.001\right)$ and gendergroups $\left(\chi^{2}(2)=32.28, p<.001\right)$. As post-hoc tests (Mann-Whitney-U) illustrate, the group of $50+$ year-old, men, and the high-income groups show less discomfort than all other groups.

\section{Cross-Country Comparison}


The three countries displayed significant differences $(p>.005)$ in all personality dimensions derived from the STAI, SVF78, PANAS and COVID-19 questionnaires (see Table 1).

The results of the pairwise post-hoc tests are shown in Table 2. On the anxiety scale, Italian participants portray significantly higher values than Austrian and German participants (State anxiety: Italy: $M=49.54, S D=3.91$; Austria: $M=43.45, S D=11.90$; Germany: $M=44.50$, $S D=12.15)$. Besides higher anxiety levels, the Italian sample shows higher negative affects (Negative Affect: Italy: $M=26.72, S D=5.28$; Austria: $M=19.88, S D=6.25$; Germany: $M=$ 21.35, $S D=6.62$ ). The Austrian and German sample do not vary significantly in this regard. With regards to stress management strategies, the Italian participants show significantly lower positive (Positive Stress Behavior: Italy: $M=12.47, S D=1.21$; Austria: $M=18.91, S D=$ 2.87; Germany: $M=18.95, S D=2.82$ ) but also significantly lower negative stress management strategies (Negative Stress Behavior: Italy: $M=12.93, S D=1.80$; Austria: $M=$ 16.37, $S D=4.57$; Germany: $M=16.32, S D=4.70)$ compared to the other two countries. The Austrian and the German samples do not differ in this regard either.

Italian respondents have significantly higher values on the COVID-19 scale Perceived severity than Austrian and German respondents (Perceived Severity of COVID-19: Italy: $M=$ $8.65, S D=1.31$; Austria: $M=8.06, S D=1.47$; Germany: $M=8.00, S D=1.57)$. They thus perceive the virus as more dangerous. All three samples differ significantly from each other regarding the perceived risk of disease. Accordingly, Germans report the highest $(M=9.18$, $S D=2.33)$, Austrians the second-highest $(M=8.59, S D=2.34)$, and Italians the lowest subjective risk of disease $(M=8.22, S D=2.24)$. The three populations also differ significantly with regards to the Emergency measures acceptance scale. The measures are most accepted by Austrians $(M=70.43, S D=6.43)$, followed by Italians $(M=69.50, S D=$ 4.72) and lastly Germans $(M=67.99, S D=8.29)$. For Emotional distress due to Emergency measures, Italians report the highest $(M=21.63, S D=6.60)$, followed by Germans $(M=$ 
$15.46, S D=6.68)$, Austrians show the lowest values $(M=13.86, S D=4.94)$. The three countries also differ significantly regarding Concerns related to the COVID19-pandemic (Italy: $M=27.61, S D=3.39$; Austria: $M=25.22, S D=5.67$; Germany: $M=26.15, S D=$ 5.79). Again, Italians show the highest and Austrians the lowest values. Item analysis show, compared to the Austrian and German sample, Italian participants report higher concern about their health (Italy: $M=3.05, S D=1.43$; Austria: $M=2.04, S D=.91$; Germany: $M=2.17, S D$ $=3.05$ ) and higher concern about financial problems (Italy: $M=3.91, S D=1.06$; Austria: $M$ $=2.12, S D=1.14$; Germany: $M=2.17, S D=1.19)$ and the economic impact of the pandemic (Italy: $M=3.69, S D=1.23$; Austria: $M=3.22, S D=1.16$; Germany: $M=3.36, S D=1.16$ ).

Regarding the use of mental health apps, Italian participants report a significantly higher usage than the participants in the other two countries (Italy: $M=1.06, S D=.65$; Austria: $M=$ $.34, S D=.64$; Germany: $M=.27, S D=.62)$. Further, attitudes towards social media have considerably changed in Italy since the start of the pandemic. $70 \%$ of the Italian respondents report that their opinion towards social media has increased since the start of the pandemic, in Austria and Germany this is only reported by $9 \%$ of the respondents.

\section{Discussion}

\section{Interpretation of the results}

The Italian participants were exposed to a lot more stressors at the time the study was conducted. They were in a phase of the pandemic, in which death and infection numbers were very high and control over the spread of the virus was only to be regained by means of very restrictive lockdown measures. In the survey phase, these measures had not yet shown much

effect. Physical stressors (danger to life and limb), social stressors (e.g., separation from friends and family, farewell from the deceased) and economic stressors (fear for work, loss of 
job) were also considerably higher than in Austria and Germany. Moreover, curfews and the associated deprivation of freedom were only in place in Italy. The severity of the pandemic, as well as the rigor of the restrictions, thus constitute two factors strongly differing between Italians, on the one hand, and Austrians and Germans, on the other. The impacts of these factors will be described by reference to our research questions in the following section.

\section{How dangerous is the virus perceived to be?}

As expected, parallel to the severity of the pandemic, Italian participants assessed the COVID-19 virus as much more dangerous, than this was the case in Austria and Germany. Likewise, Italian participants also portray significantly higher levels of worries associated with the virus. Presumably, because of the comparably high mortality in Italy and the related threat to life, the individual worry to fall ill with COVID-19 is higher than in Austria and Germany.

How high is the subjective risk of disease perceived in dependency on the emergency measures?

Despite the prevalence of the virus, the subjective risk of disease is perceived to be lower in Italy than in Austria and Germany. This could be a positive effect of the restrictive curfews. At the time of the survey, the Italian participants had already experienced 14 days of lockdown and hence had barely any opportunity to get infected with the virus outside their own household. The infection risk was probably indeed lower. The opposite was true for the German participants, for whom the lockdown had only just started and no curfews had yet been implemented. The risk of catching the virus was thus still comparatively high for this subpopulation and the subjective risk of disease was consequently assessed to be higher. In Austria, the perceived subjective risk of disease was significantly lower than in Germany. Presumably, this was because the restrictions had already been in place for a week at the time. 
How does the acceptance of the statutory emergency measures develop and which emotions accompany the respective measures?

Concerning the acceptance of the measures, the Italian population took a middle position between Austria and Germany. The measures set by the government were generally perceived to be very effective in all three countries. This means that even the Italian participants, who had to endure the most restrictions, showed high levels of acceptance. As expected, the emotional reaction (anger, fear) was the strongest within the Italian sample. It can be assumed that the duration and the severity of the measures did not only lead to generally high levels of emotional stress, but more concretely, also contributed to worries related to financial and economic future repercussions in Italy. This is particularly problematic, as Italy is overall economically weaker than Germany and Austria, which can be seen in the lower annual income of the subpopulation, despite the same educational level. In Austria, the comparatively less restrictive measures were accepted to a high degree and caused considerably less emotional stress. This is true, despite the fact that the Austrian subpopulation was significantly younger than the Italian one, and, as it turned out in the analyses, younger people showed stronger emotional reactions in the crises and lower levels of acceptance of the measures. In the German sample, in which the statutory measures resembled the ones in Austria, the level of emotional stress was very similar to the one in the Austrian sample and likewise comparatively low. However, while there was a high degree of approval of the measures, it was lower than in the other two countries.

Which effects do the statutory measures have on fear and emotional wellbeing of the population?

Despite the very restrictive statutory containment measures, the Italian sample shows considerably higher anxiety values and higher negative affect than in Austria and Germany. Since - as mentioned above - the worries associated with the corona pandemic, and in 
particular the financial and economic worries, were higher as well, the impression arises that fear is nurtured by the anticipated negative repercussions of the strong restrictions on the already weakened economy of the country. It presumably also caused distress that, at the time of the study, the infection numbers in Italy were very high, despite the restrictive measures. The country faced thus overall a dramatic crisis

\section{Which coping strategies can become effective under the respective measures?}

Highly emotionally stressed due to the restrictive measures, Italians could draw comparatively less on positive stress processing strategies, according to our study. In SVF78 they score the lowest values on the scale Positive stress behavior. However, this is also due to the sever restrictive measures: the subscales of Positive stress behavior: Diversion, compensatory satisfaction, situation control and Social support measure strategies that are difficult to implement under these circumstances. The comparatively high usage of mental health apps can be interpreted as an attempt of self-stabilization by means of stress management in the sense of a badly needed distraction and compensatory satisfaction, but also as a need for social support. The markedly positive change in attitudes towards social media indicates the importance of this medial mediated social compensation in coping with the crisis. At first sight, it might seem odd that negative Stress processing mechanisms - which lead to a shortterm stress reduction, but increase the stress burden long-term - are also lower in the Italian sample than in the other two countries. However, the individual scales show, that the negative stress processing strategies Avoidance and Escape tendency could not be implemented due to the restrictions and that there was hardly any reason for Self-accusation in a pandemic, in which control was lost over the virus and thus contagion changes could no longer be traced. The Perseveration strategy was potentially lower due to a "numbness" setting in after 14 days of lockdown, as opposed to Austrians and Germans, for which the drama of the happenings 
was comparatively new, as they were still at the beginning of the lockdown, i.e. the beginning of the phase in which governments had to counteract as control seemed to slip away.

\section{Summary of the Results and Implications}

Overall, the Italian population perceived the virus comparatively more dangerous. This corresponded to the pandemic situation within the country, at the time of the study. However, the subjective risk of disease was judged to be lower, as restrictive emergency measures went hand in hand with a lower risk of infection. At the same time, the emotional stress associated with the very restrictive lockdown conditions, practically equaling confinement to the own apartment, was reported to be much higher. Additionally, it became apparent that the measures did not alleviate the prevalent fear of the population. The stricter measures also prevented an application of many stress processing strategies such as diversion, compensatory satisfaction and social support, which, in turn, fostered the preservation of stresses and fear. Our study thus shows through the comparison of countries with restrictive and moderate lockdown measures, that such massive constraints to the containment of the virus may make sense from an epidemiological point of view, but exceed the coping capabilities of the population and do not reduce fear. The opposite is true: Such massive constraints to freedom contribute to additional stress, which manifests itself in our study in considerably increased negative affect. Consequently, it is in accordance with the bio-medical-psychosocial model, also necessary during pandemics (3) to reconcile epidemiological protective strategies with psychosocial coping capabilities in the best way possible. This means, that necessary lockdowns should be designed in a way, that does not overwhelm the emotional stress capabilities of the population. Otherwise the consequence can be expected to be highly prevalent secondary diseases due to stress. It has been shown that during the lockdown the number of mental disorders has quadrupled (28) and suicide rates have increased enormously. 
Current estimates assume that there will be between 2135 and 9570 additional suicides worldwide in the context of the COVID-19-Pandemic (17).

The same problems are reflected in the increase of digital media usage such as online-gaming or social media. Despite the fact, that the opportunity to digitally exchange with family and friends during the lockdown and thus to experience social support without social-physical presence or simply receive entertainment, proved to be a constructive coping strategy $(6,11)$, studies have shown that addictive media usage increased during the lockdown (32). This is not surprising when digital communication and instrumental media usage for emotion regulation, remain one of the last possibilities to satisfy socio(physical) needs.

\section{Methodological Limitations}

The strongest limitations of this study result from online recruitment (forums and social media platforms) applying the snowball sampling procedure. This non-probability sampling technique may reflect the bias in the self-selection of the participants whose central characteristics do not correspond to the German and Austrian population. The sample in this

study, for instance, has a higher proportion of women with a high level of education. At the same time, as data obtained from self-assessment does not constitute an accurate representation of behaviors, statements about the actual compliance with emergency measures require caution. However, since the survey was anonymous, we can presume a low social desirability tendency, although recall biases may influence self-assessment (see retrospection effect, e.g., Gorin \& Stone, 2001).

\section{Research Outlook}

Our findings should be replicated in further studies with a representative sample. Qualitative interviews could capture the emotional wellbeing of the population groups, which have 
experienced different degrees of severity of the pandemic, in depth. A quantitative analysis of media coverage and the information policy of the respective governments could help to understand why, for example, there is a higher approval of the measures in Austria than in Germany, despite the measures being very similar in content. While studies have already proven that there is an influence of information consumed via social networks, in terms of increased levels of anxiety and stress (for an overview see 15, in press), no study contrasting countries with varying degrees of the pandemic, has been conducted. 


\section{Declaration}

\section{Ethics approval and consent to participate}

The study involving human participants was reviewed and approved by the Ethics Commission of the Faculty of Psychotherapy Science and the Faculty of Psychology, Sigmund Freund University Vienna. The participants provided their written informed consent to participate in this study. The Ethics Commission of the Sigmund Freud University approved the methods used in this study in accordance with the relevant guidelines and regulations.

Committees reference number: RBMDKD5QALCJC487790

Date of approval: March 18th 2020

\section{Consent for publication:}

Not applicable.

\section{Availability of data and materials:}

The datasets used and/or analysed during the current study are available from the corresponding author on reasonable request.

\section{Competing interests:}

The authors declare that they have no competing interests.

\section{Funding:}

This work was supported by the Medical Scientific Fund of the Mayor of the Federal Capital Vienna, Austria.

\section{Author's contributions:}


CE created the study design, developed the patient's questionnaire, collected and interpreted participant data and co-wrote the manuscript. MG evaluated participant data. GR developed the patient's questionnaire as well as collected participant data. RB collected participant data. SH.-B conducted data evaluation, interpreted participant data and co-wrote the manuscript. SK supervised this study. All authors read and approved the final manuscript.

\section{Acknowledgements:}

Not applicable. 


\section{References}

1. Attias D, Pepin J, Pathak A. Impact of COVID-19 lockdown on adherence to continuous positive airway pressure by obstructive sleep apnoea patients. European Respiratory Journal. 2020;56(1):2001607.

2. Balhara Y, Kattula D, Singh S, Chukkali S, Bhargava R. Impact of lockdown following COVID-19 on the gaming behavior of college students. Indian Journal of Public Health. 2020;64(6):172.

3. Bering R, Eckhard A. Das bio-psycho-soziale Modell der pandemischen Stressbelastung. Bering R, Eichenberg C (eds). Die Psyche in Zeiten der Corona-Krise. Herausforderungen und Lösungsansätze für Psychotherapeuten und soziale Helfer. Stuttgart : Klett-Clotta;; 2020. p.43 - 53.

4. Bering R, Eichenberg C. Die Psyche in Zeiten der Corona-Krise. Herausforderungen und Lösungsansätze für Psychotherapeuten und soziale Helfer. Stuttgart: Klett-Cotta; 2020.

5. Bobo E, Lin L, Acquaviva E, Caci H, Franc N, Gamon L et al. Comment les enfants et adolescents avec le trouble déficit d'attention/hyperactivité (TDAH) vivent-ils le confinement durant la pandémie COVID-19 ?. L'Encéphale. 2020;46(3):S85-S92.

6. Cauberghe V, Van Wesenbeeck I, De Jans S, Hudders L, Ponnet K. How Adolescents Use Social Media to Cope with Feelings of Loneliness and Anxiety During COVID-19

Lockdown. Cyberpsychology, Behavior, and Social Networking. 2020 Oct 20.

7. Cerbara L, Ciancimino G, Crescimbene M, La Longa F, Parsi M.R., Tintori A, Palomba R. A nation-wide survey on emotional and psychological impacts of COVID-19 social distancing. European review for medical and pharmacological sciences 2020; 24 (12)

8. Dsouza DD, Quadros S, Hyderabadwala ZJ, Mamun MA. Aggregated COVID-19 suicide incidences in India: Fear of COVID-19 infection is the prominent causative factor. Psychiatry Research. 2020:113145.

9. Eichenberg, C., Grossfurthner, M. \& Andrich, J. et al. (under review). Relationship between the implementation of statutory preventive measures and personality traits in the initial stage of corona-related lockdown: A German and Austrian population online survey.

10. Erdmann G, Janke W. SVF. Stressverarbeitungsfragebogen. Stress, Stressverarbeitung und ihre Erfassung durch ein mehrdimensionales Testsystem, (4. überarb. \& erw. Aufl.) ed. Göttingen: Hogrefe; 2020.

11. Gabbiadini A, Baldissarri C, Durante F, Valtorta RR, De Rosa M, Gallucci M. Together Apart: The Mitigating Role of Digital Communication Technologies on Negative Affect During the COVID-19 Outbreak in Italy. Front Psychol. 2020 Oct 21;11

12. Gerlach A, Andor T, Patzelt J. Die Bedeutung von Unsicherheitsintoleranz für die Generalisierte Angststörung Modellüberlegungen und Entwicklung einer deutschen Version der Unsicherheitsintoleranz-Skala. Zeitschrift für Klinische Psychologie und Psychotherapie 37. 2008;190-199. 
13. Gupta AK, Sahoo S, Mehra A, Grover S. Psychological impact of 'Lockdown' due to COVID-19 pandemic in Nepal: An online survey. Asian Journal of Psychiatry.

2020;54:102243.

14. Hao F, Tan W, Jiang L, Zhang L, Zhao X, Zou Y, et al. Do psychiatric patients experience more psychiatric symptoms during COVID-19 pandemic and lockdown? A case-control study with service and research implications for immunopsychiatry. Brain, Behavior, and Immunity. 2020;87:100-6.

15. Huss, J. \& Eichenberg, C. Psychotraumatologische Abwehrmechanismen in der medialen Berichterstattung am Beispiel der COVID-19-Pandemie. In R. Bering u. C. Eichenberg (Hrsg.), Die Psyche in Zeiten der Corona-Krise. Herausforderungen und Lösungsansätze für Psychotherapeuten und soziale Helfer. (in press). Stuttgart: Klett-Clotta.

16. Jacob L, Smith L, Butler L, Barnett Y, Grabovac I, McDermott D, et al. Challenges in the Practice of Sexual Medicine in the Time of COVID-19 in the United Kingdom. The Journal of Sexual Medicine. 2020;17(7):1229-36.

17. Kawohl W, Nordt C. COVID-19, unemployment, and suicide. The Lancet Psychiatry. 2020;7(5):389-90.

18. Kim A.W, Nyengerai T, Mendenhall E. Evaluating the Mental Health Impacts of the COVID-19 Pandemic in Urban South Africa: Perceived Risk of COVID-19 Infection and Childhood Trauma Predict Adult Depressive Symptoms. medRxiv. 2020 Jun16:

2020.06.13.20130120.

19. Kumar K, Mehra A, Sahoo S, Nehra R, Grover S. The psychological impact of COVID-19 pandemic and lockdown on the migrant workers: A cross-sectional survey. Asian Journal of Psychiatry. 2020;53:102252.

20. Laux, L., Glanzmann, P. Schaffner, P. Das State-Trait-Angstinventar. Göttingen: Hogrefe 1981.

21. López J, Perez-Rojo G, Noriega C, Carretero I, Velasco C, Martinez-Huertas J, et al. Psychological well-being among older adults during the COVID-19 outbreak: a comparative study of the young-old and the old-old adults. International psychogeriatrics.

2020;32(11):1365-70.

22. Marelli S, Castelnuovo A, Somma A, Castronovo V, Mombelli S, Bottoni D, et al. Impact of COVID-19 lockdown on sleep quality in university students and administration staff. Journal of Neurology. 2020 July 11.

23. Moccia L, Janiri D, Pepe M, Dattoli L, Molinaro M, De Martin V, et al. Affective temperament, attachment style, and the psychological impact of the COVID-19 outbreak: an early report on the Italian general population. Brain, Behavior, and Immunity. 2020;87:75-9.

24. Nese M, Riboli G, Brighetti G, Sassi V, Camela E, Caselli G, et al. Delay discounting of compliance with containment measures during the COVID-19 outbreak: a survey of the Italian population. Journal of Public Health (Berl). 2020 Jun:1-9.

25. Odriozola-González P, Planchuelo-Gómez Á, Irurtia MJ, de Luis-García R. Psychological effects of the COVID-19 outbreak and lockdown among students and workers of a Spanish university. Psychiatry Research. 2020;290:113108. 
26. Parodi IC, Poeta MG, Assini A, Schirinzi E, Del Sette P. Impact of quarantine due to COVID infection on migraine: a survey in Genova, Italy. Neurological Sciences. 2020;41(8):2025-7.

27. Parrado-González A, León-Jariego JC. [Covid-19: factors associated with emotional distress and psychological morbidity in spanish population. Rev Esp Salud Publica. 20208;94:e202006058.

28. Pierce M, Hope H, Ford T, Hatch S, Hotopf M, John A, et al. Mental health before and during the COVID-19 pandemic: a longitudinal probability sample survey of the UK population. The Lancet Psychiatry. 2020;7(10):883-92.

29. Qin F, Song Y, Nassis GP, Zhao L, Dong Y, Zhao C, et al. Physical Activity, Screen Time, and Emotional Well-Being during the 2019 Novel Coronavirus Outbreak in China. International journal of environmental research and public health. 2020;17(14):5170.

30. Ren X, Huang W, Pan H, Huang T, Wang X, Ma Y. Mental Health During the Covid-19 Outbreak in China: a Meta-Analysis. Psychiatric Quarterly. 2020;91(4):1033-45.

31. Rimfeld K, Malancini M, Allegrini A, Packer AE, McMillan A, Ogden R, et al. Genetic correlates of psychological responses to the COVID-19 crisis in young adult twins in Great Britain. Research square. 2020; 27:rs.3.rs-31853.

32. Rolland B, Haesebaert F, Zante E, Benyamina A, Haesebaert J, Franck N. Global Changes and Factors of Increase in Caloric/Salty Food Intake, Screen Use, and Substance Use During the Early COVID-19 Containment Phase in the General Population in France: Survey Study. JMIR Public Health Surveill. 2020;6(3):e19630.

33. Sax L, Gilmartin S, Bryant A. Assessing response rates and nonresponse bias in web and paper surveys. Research in Higher Education. 2003; 44(4):409-32

34. De Sio S, Buomprisco G, La Torre G, Lapteva E, Perri R, Greco E, et al. The impact of COVID-19 on doctors' well-being: results of a web survey during the lockdown in Italy. European review for medical and pharmacological sciences. 2020 07;24(14):7869-79.

35. Su Y, Xue J, Liu X, Wu P, Chen J, Chen C, et al. Examining the Impact of COVID-19 Lockdown in Wuhan and Lombardy: A Psycholinguistic Analysis on Weibo and Twitter. International journal of environmental research and public health. 2020;17(12):4552.

36. Watson D, Clark LA, Tellegen A. Development and validation of brief measures of positive and negative affect: the PANAS scales. J Pers Soc Psychol 1988; 54(6):1063-7 
Table 1:

Descriptive Statistics and Kruskal-Wallis Tests results for personality and COVID-19-scales

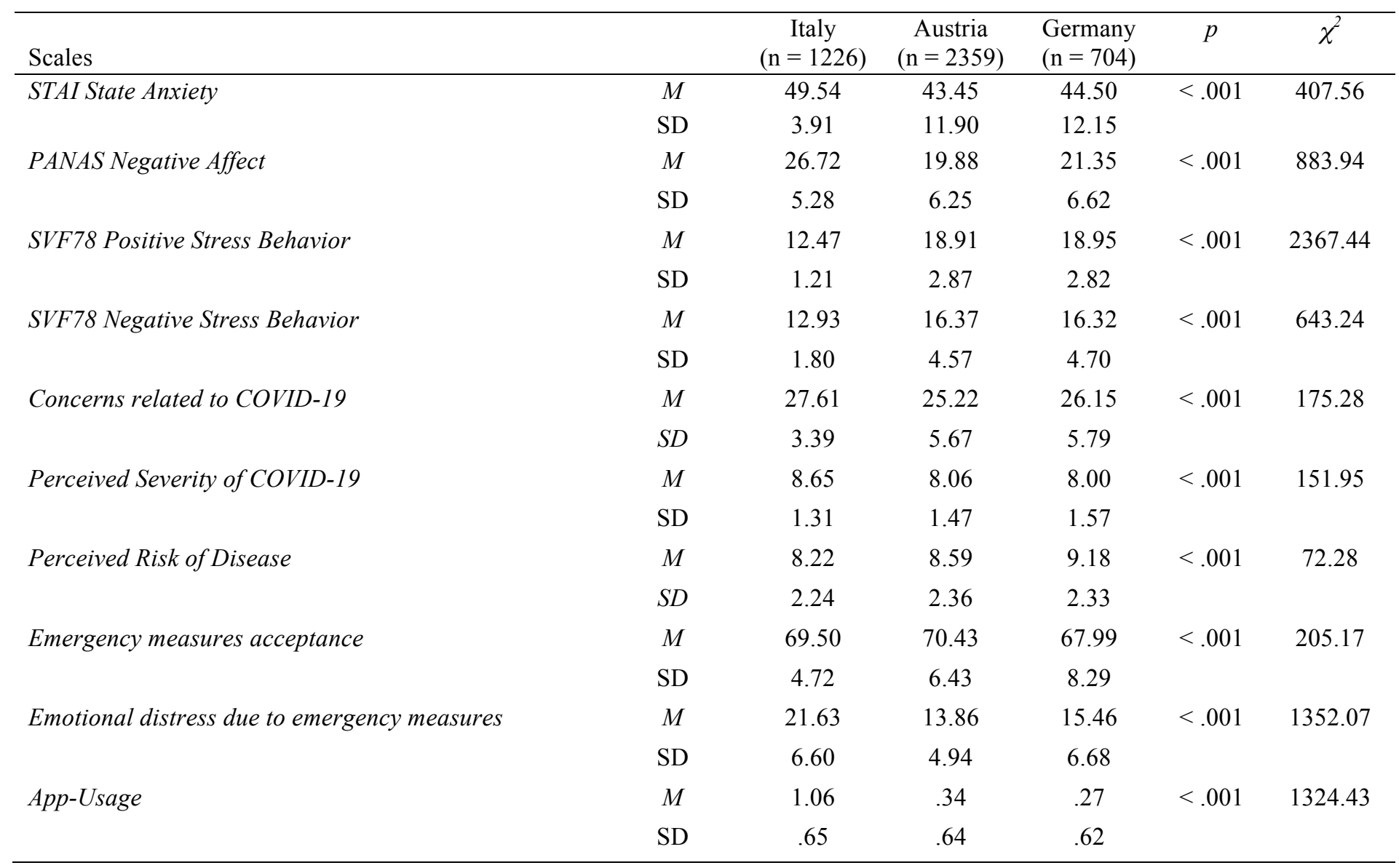


Table 2:

Mann-Whitney-U-Test post hoc tests

\begin{tabular}{|c|c|c|c|c|}
\hline Personality und demographic measures & group & group & $p$ & $r$ \\
\hline \multirow[t]{3}{*}{ STAI State Anxiety } & Italy & Austria & $<.001$ & 0.33 \\
\hline & Italy & Germany & $<.001$ & 0.29 \\
\hline & Austria & Germany & .049 & \\
\hline \multirow[t]{3}{*}{ PANAS Negative Affect } & Italy & Austria & $<.001$ & 0.50 \\
\hline & Italy & Germany & $<.001$ & 0.40 \\
\hline & Austria & Germany & $<.001$ & 0.10 \\
\hline \multirow[t]{3}{*}{ SVF78 Positive Stress Behavior } & Italy & Austria & $<.001$ & 0.78 \\
\hline & Italy & Germany & $<.001$ & 0.80 \\
\hline & Austria & Germany & .761 & \\
\hline \multirow[t]{3}{*}{ SVF78 Negative Stress Behavior } & Italy & Austria & $<.001$ & 0.41 \\
\hline & Italy & Germany & $<.001$ & 0.41 \\
\hline & Austria & Germany & .587 & \\
\hline \multirow[t]{3}{*}{ Concerns related to COVID-19 } & Italy & Austria & $<.001$ & 0.22 \\
\hline & Italy & Germany & $<.001$ & 0.15 \\
\hline & Austria & Germany & $<.001$ & 0.07 \\
\hline \multirow[t]{3}{*}{ Perceived Severity of COVID-19 } & Italy & Austria & $<.001$ & 0.20 \\
\hline & Italy & Germany & $<.001$ & 0.21 \\
\hline & Austria & Germany & .631 & \\
\hline \multirow[t]{3}{*}{ Perceived Risk of Disease } & Italy & Austria & $<.001$ & 0.07 \\
\hline & Italy & Germany & $<.001$ & 0.20 \\
\hline & Austria & Germany & $<.001$ & 0.11 \\
\hline \multirow[t]{3}{*}{ Emergency measures acceptance } & Italy & Austria & $<.001$ & 0.22 \\
\hline & Italy & Germany & .434 & \\
\hline & Austria & Germany & $<.001$ & 0.16 \\
\hline \multirow[t]{3}{*}{ Emotional distress due to emergency measures } & Italy & Austria & $<.001$ & 0.44 \\
\hline & Italy & Germany & $<.001$ & 0.34 \\
\hline & Austria & Germany & $<.001$ & 0.10 \\
\hline
\end{tabular}

Note. Effect sizes: $r=0.10$ small, $r=.30$ medium, $r=.50$ large (Cohen, 1988) 



\section{Supplementary Files}

This is a list of supplementary files associated with this preprint. Click to download.

- APPENDIXTranslationoftheCovid19pandemicquestionnaire.docx 